\title{
Potencial de captação de água de chuva em unidades familiares rurais do município de Breves-PA
}

\author{
FREIRES, Evelyn Lopes ${ }^{1}$ \\ MENDES, Herbert Maracaípe ${ }^{2}$ \\ MENDES, Ronaldo Lopes Rodrigues ${ }^{3}$ \\ RAMOS, Francisca Correa Dias ${ }^{4}$

\begin{abstract}
1UFPA, Universidade Federal do Pará, Belém, Brasil. evelyn.lopes16@gmail.com 2UNIFESSPA, Universidade Federal do Sul e Sudeste do Pará, Marabá, Brasil. herbert.maracaipe@gmail.com

${ }^{3}$ UFPA, Universidade Federal do Pará, Belém, Brasil.rlrmendes@ufpa.br

4UFPA, Universidade Federal do Pará, Belém, Brasil. sararamosbaiao@gmail.com
\end{abstract}

\begin{abstract}
Resumo
A zona rural da Amazônia possui uma particularidade muito grande, principalmente nas comunidades ribeirinhas: geralmente são caracterizadas pela carência de saneamento básico. No cenário paraense, cerca de $60 \%$ dos municípios apresentam sistema de abastecimento ineficiente, decorrente de dificuldades na oferta de água nos mananciais, em quantidade e/ou qualidade (ANA, 2010). O presente estudo visa avaliar o potencial de aproveitamento doméstico da água da chuva em unidades familiares de áreas rurais do município de Breves. A metodologia utilizada se pautou inicialmente um uma pesquisa exploratória, a partir do material bibliográfico e documental. Assim, a escala espacial da pesquisa abrangeu as unidades familiares rurais existentes no município de Breves, pertencente à mesorregião do Marajó, no Pará, do qual buscou-se calcular o potencial de aproveitamento da água pluvial, considerando os seguintes dados de precipitação mensal; área de captação total; e população rural (Ghisi et al., 2006). Além disso, o volume de precipitação a ser coletado variou entre $84,9 \mathrm{~m}^{3} / \mathrm{mês}$ a $1580,90 \mathrm{~m}^{3} / \mathrm{mês}$, revelando como grande potencial em comunidades rurais, o aproveitamento doméstico a partir da captação da água pluvial, como forma de sanar a carência do acesso ao recurso hídrico para consumo humano.
\end{abstract}

Palavras-Chave: pluviosidade; Breves; captação; potencial; unidades familiares; rural.

\begin{abstract}
The Amazonian rural zone has a very great peculiarity, mainly in the riverside communities: they are usually characterized by the lack of basic sanitation. In the Paraense scenario, about $60 \%$ of the municipalities have an inefficient supply system, due to difficulties in supplying water in the water sources, in quantity and / or quality (ANA, 2010). The present study aims to evaluate the potential of domestic use of rainwater in family units in rural areas of the municipality of Breves. The methodology used was initially based on an exploratory research, based on bibliographical and documentary material. Thus, the spatial scale of the research encompassed rural households in the municipality of Breves, belonging to the Marajó mesoregion, in Pará, from which the potential for utilization of rainwater was calculated, considering the following monthly precipitation data; catchment area and the total; e rural population (Ghisi et al., 2006). In addition, the volume of precipitation to be collected ranged from $84.9 \mathrm{~m}^{3} /$ month to $1580.90 \mathrm{~m}^{3} /$ month, revealing as a great potential in rural communities, the domestic use from the rainwater harvesting, as a way to remedy the shortage access to water resources for human consumption.
\end{abstract}

Key-Words: rainfall; Briefs; capture; potential; family units; rural. 


\section{Introdução}

Os conflitos pelo uso da água são recorrentes em toda a história da humanidade. O que se modifica é a forma como as sociedades se organizam para enfrentá-los. A água doce é o recurso vital para sobrevivência das civilizações e, em casos de escassez, constitui-se como fator limitante na implementação de atividades econômicas típicas das sociedades modernas. A intensificação do uso da água, causada pela ampliação da produção de alimentos e demais bens de consumo, provocou problemas ambientais ameaçando, inclusive, sua conservação.

Nesse sentido, a Amazônia é da maior importância para o equilíbrio hídrico global e continental. Abrange uma área de, aproximadamente 6 milhões de $\mathrm{km}^{2}$, se estendendo por sete países: Brasil, Colômbia, Bolívia, Equador, Guiana, Peru e Venezuela. A bacia amazônica corresponde a $45 \%$ do território nacional, representando cerca de $20 \%$ de toda a água doce superficial do mundo alcançando vazões da ordem de $74 \mathrm{mil} \mathrm{m} 3 / \mathrm{s}$, destacando dentre os seus principais rios: Purus, Juruá, Xingu, Solimões, Madeira, Negro e Guaporé (ANA, 2010).

Diante desse cenário, a busca de água doce para atender às demandas e suas necessidades hídricas, obrigou o homem a elaborar tecnologias para armazenar e captar água nas regiões áridas e semiáridas, possibilitando que o modelo atual da gestão dos recursos hídricos torne o aproveitamento desta água não apenas como estratégia de abastecimento das populações dessas regiões, mas, também, como medida de mitigação de risco e estratégia de sua conservação (BRITO et al., 2015).

A zona rural da Amazônia possui uma particularidade muito grande, principalmente nas comunidades ribeirinhas: geralmente são caracterizadas pela carência de saneamento básico. $\mathrm{Na}$ Amazônia paraense são milhares de vilarejos, comunidades, núcleos e ilhas com abundância em água superficial, ou seja, a quantidade de água não é a dificuldade, o entrave maior é a qualidade adequada. São áreas geralmente de acesso difícil realizado por via fluvial, estando as casas distantes umas das outras. Essas características tornam inviáveis economicamente a instalação de um sistema público coletivo de água. $\mathrm{O}$ abastecimento de água na maioria dessas comunidades acontece por meio dos mananciais superficiais, subterrâneos (através de cacimbas ou poços rasos), transporte de água por longas distâncias das cidades mais próximas ou combinação dessas soluções. Essas fontes nem sempre são adequadas ao consumo.

Nesse sentido, as tecnologias de captação e manejo de água de chuva surgem como alternativas técnicas que permitem interceptar e utilizar a água de chuva no local onde ela cai no chão; que facilitam a água da chuva a se infiltrar no solo; ou que captam a água de escoamento de uma área específica (telhados, pátios, chão, ruas e estradas) para depois ser armazenada em um reservatório (cisterna ou solo) para uso futuro, seja doméstico, agrícola, dessedentação de animais ou ambiental, tanto em áreas rurais como urbanas. A vantagem da água de chuva é ser uma fonte de água diretamente acessível onde cai que fica disponível para quando se precisa dela sem uso adicional de energia (BRITO et al., 2015).

No cenário paraense, cerca de $60 \%$ dos municípios apresentam sistema de abastecimento ineficiente, decorrente de dificuldades na oferta de água nos mananciais, em quantidade e/ou qualidade (ANA, 2010). Essa realidade se agrava principalmente em comunidades ribeirinhas da Amazônia, onde os moradores não possuem acesso à distribuição de água tratada, levando-os a ingerir diretamente dos rios sem nenhum tipo de tratamento ou que paguem por qualidade duvidosa, fato este que revela a existência de um comércio diante do direito à água potável.

Portanto, o presente estudo visa avaliar o potencial de aproveitamento doméstico da água da chuva em unidades familiares de áreas rurais do município de Breves, como forma de sanar a carência do abastecimento de água potável dessas regiões, bem como promover uma melhoria significativa da qualidade de vida dessas populações.

\section{Desenvolvimento}

\subsection{Metodologia}

A metodologia utilizada se pautou inicialmente um uma pesquisa bibliográfica e documental (consultas em livros, teses, dissertações e artigos científicos), objetivando-se possibilitar maior familiaridade com o problema e a área pesquisada, bem como fundamentar e compreender os conceitos relacionados ao tema central da pesquisa. A ordem de classificação da metodologia objetivou gerar conhecimentos que pudessem nortear a percepção do desenvolvimento endógeno local, como premissa essencial para a promoção da pesquisa exploratória (PRODANOV; FREITAS, 2013).

Além disso, outra forma de abordagem utilizada no presente trabalho consistiu em uma Pesquisa Quantitativa, no qual traduz em números opiniões e informações para classificá-los e 
organiza-las, assim como da aplicação de métodos estatísticos, do qual buscou-se calcular o potencial de aproveitamento da água pluvial, considerando os seguintes dados de precipitação média mensal, a área do telhado e a porcentagem de casas na zona rural de Breves (GHISI et al., 2006).

\subsection{Caracterização da área de estudo}

A área de abrangência da pesquisa compreende o município de Breves (com uma área territorial de 9.550,513 km2), pertencente à mesorregião do Marajó e microrregião Furos de Breves, no Estado do Pará. Geograficamente, o Marajó (Figura 1) é constituída de três Microrregiões (MR): Arari, Portel e Furos de Breves, sendo que as duas primeiras MR abrangem municípios inseridos completamente no Arquipélago do Marajó, enquanto que a MR de Breves compreende os municípios (Afuá, Anajás, Breves, Curralinho e São Sebastião da Boa Vista) com sedes em territórios continentais (CALVIS et al., 2016; IBGE, 2010).

Figura 1: Mapa de localização dos municípios Arquipélago do Marajó, estado do Pará.

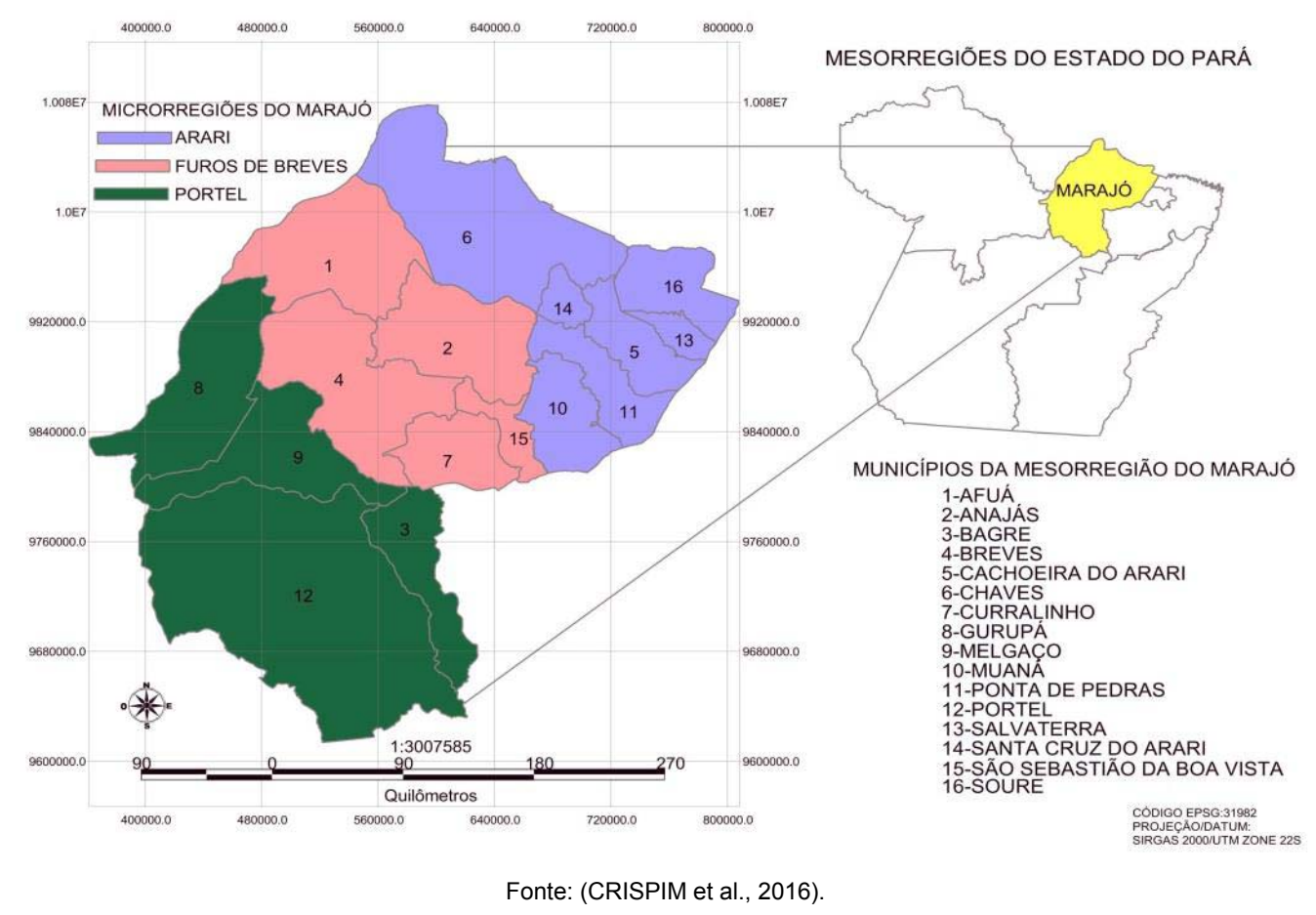

Localizada no extremo norte do Estado do Pará, que engloba a foz do rio Amazonas, o Marajó apresenta como limites: ao norte o Estado do Amapá e o Oceano Atlântico; ao sul o rio Pará; a leste a Baía do Marajó; e a oeste o estado do Amapá. Com uma área total de 59.308,40 km2, corresponde cerca de 4,7 \% do Estado. A relevância ecológica da Ilha do Marajó, atualmente, não é contemplada com planos de gestão ambiental e hídrica que minimizem as intervenções sofridas, representando um grande desafio à sua sociobiodiversidade (LIMA et al., 2004).

A hidrografia é representada pelo emaranhado de furos, paranás e igarapés. O rio Jacaré Grande é o mais importante e se intercomunica com vários furos e igarapés, em todas as direções, sendo o maior deles, o Furo dos Macacos, que vai até o sul do município, e interliga-se com outros furos, inclusive o rio Parauhaú, onde se encontra a sede do municipal. O rio Jacaré Grande deságua no central do Vieira Grande, no norte do município e esse, por sua vez comunica-se com o Amazonas (FUNDAÇÃO AMAZÔNIA DE AMPARO A ESTUDOS E PESQUISAS, 2016).

\subsection{Fundamentação Teórica}

\subsubsection{Saneamento Básico}

A Pesquisa Nacional de Saneamento Básico, realizada em 2008 revelou que a região amazônica brasileira permanece apresentando o maior déficit nacional em termos de abastecimento de água. A pesquisa revela que $54,7 \%$ dos domicílios amazônicos não têm acesso à rede geral e que 
apenas 10,5\% dos municípios da região possuem formas alternativas de abastecimento (IBGE, 2010). Além disso, segundo a mesma fonte, dentre os municípios que em 2008 distribuíam água sem qualquer tipo de tratamento, $20,8 \%$ estão situados na região, com destaque para os estados do Pará (40\% dos municípios) e Amazonas (38,7\% dos municípios).

De acordo com IBGE (2017), o município de Breves representa apenas $6.1 \%$ de domicílios com esgotamento sanitário adequado. Quando comparado com os outros municípios do estado, fica na posição $91^{\circ}$ de 144 . Já quando comparado a outras cidades do Brasil, sua posição é 4.698 de 5.570 (Figura 2).

Figura 2: Indicação da posição do município de Breves quanto ao saneamento básico.

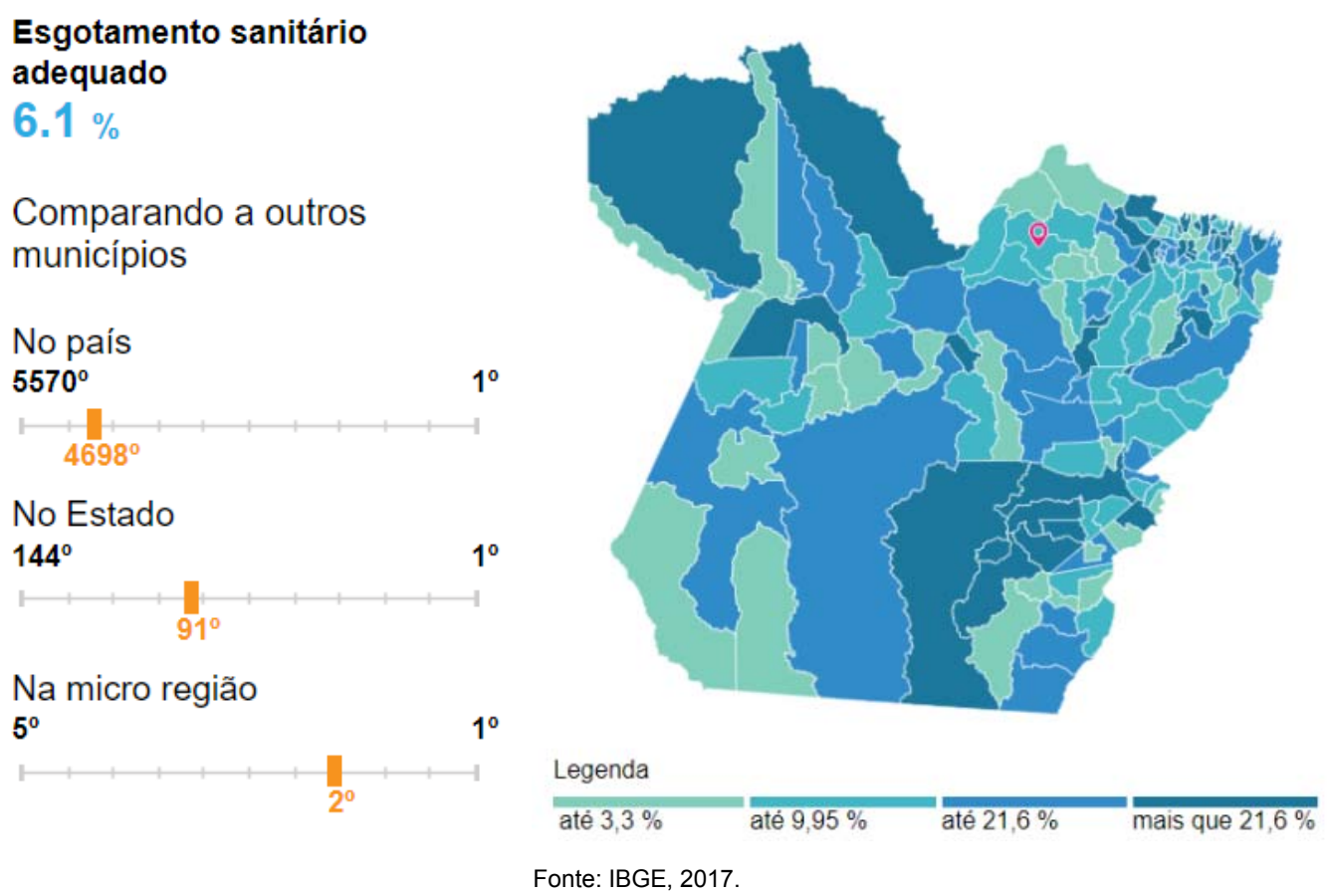

Segundo dados disponíveis no diagnóstico dos serviços de água e esgoto, do total de 97.351 habitantes de Breves em 2014, apenas 48.812 eram residentes da área urbana e 48.539 pertencentes à área rural. $\mathrm{O}$ atendimento com abastecimento de água atingia somente 25.812 habitantes, sendo todos residentes da área urbana. Esses números mostram que apenas $52,9 \%$ da população urbana de Breves possuía acesso aos serviços de abastecimento de água oferecido pela COSANPA (SNIS, 2016a). Esse valor corresponde a $26,52 \%$ da população total de Breves atendida com abastecimento de água. Os números citados estão reunidos na Tabela 1.

Tabela 1: População residente e população atendida com serviço de abastecimento de água, no município de Breves no ano de 2014.

\begin{tabular}{lccc}
\hline Área & $\begin{array}{c}\text { População } \\
\text { (Hab.) }\end{array}$ & $\begin{array}{c}\text { População atendida pelo SAA } \\
\text { da COSANPA (hab.) }\end{array}$ & $\begin{array}{c}\text { População atendida pela COSANPA } \\
\text { (\%) }\end{array}$ \\
\hline Urbana & 48.812 & 25.817 & 52,9 \\
Rural & 48.539 & 0 & 0 \\
Total & 97.351 & 25.817 & 26,52 \\
\hline \multicolumn{4}{r}{ Fonte: SNIS, 2016a. }
\end{tabular}

\subsubsection{Pluviosidade}

A disponibilidade hídrica foi obtida através das médias de pluviosidade da região de Breves (Figura 3), considerando a série histórica de 2000 a 2010, conforme os dados fornecidos pelo Instituto Nacional de Meteorologia (INMET, 2011). 
Figura 3: Média da pluviosidade do município de Breves, no intervalo de 2000 a 2010.

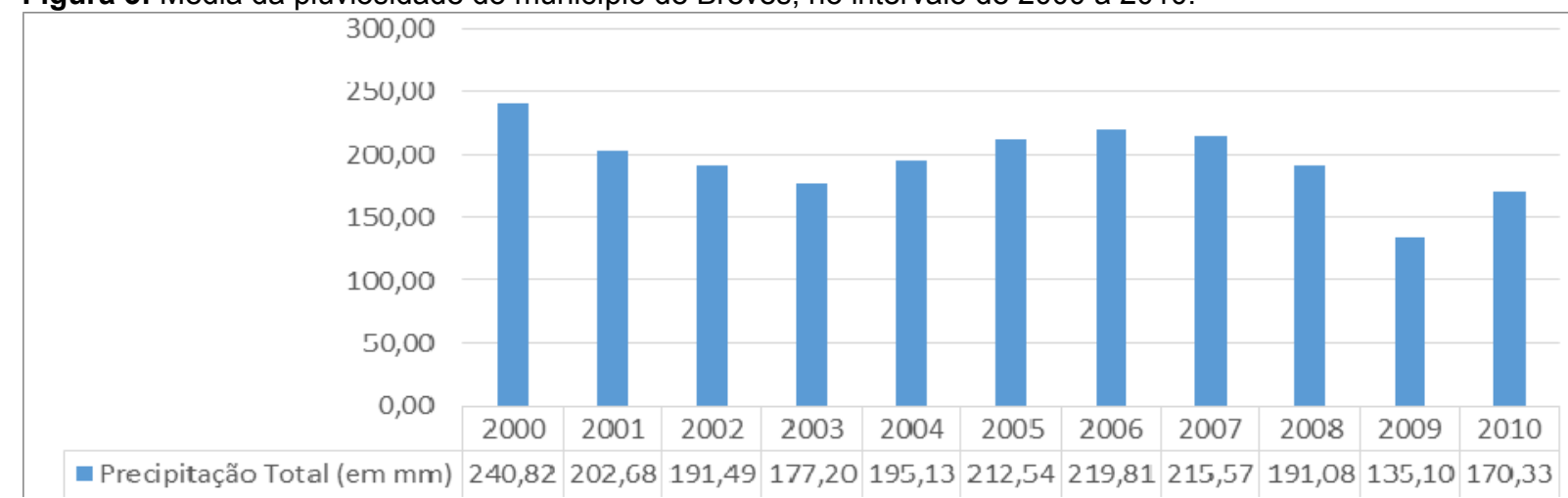

Fonte: INMET, 2011.

Além disso, observou-se que nesse intervalo, os meses mais chuvosos compreenderam-se entre dezembro a junho, de acordo com Figura 4.

Figura 4: Série histórica dos anos 2000 a 2010, quanto à chuva acumulada mensal.
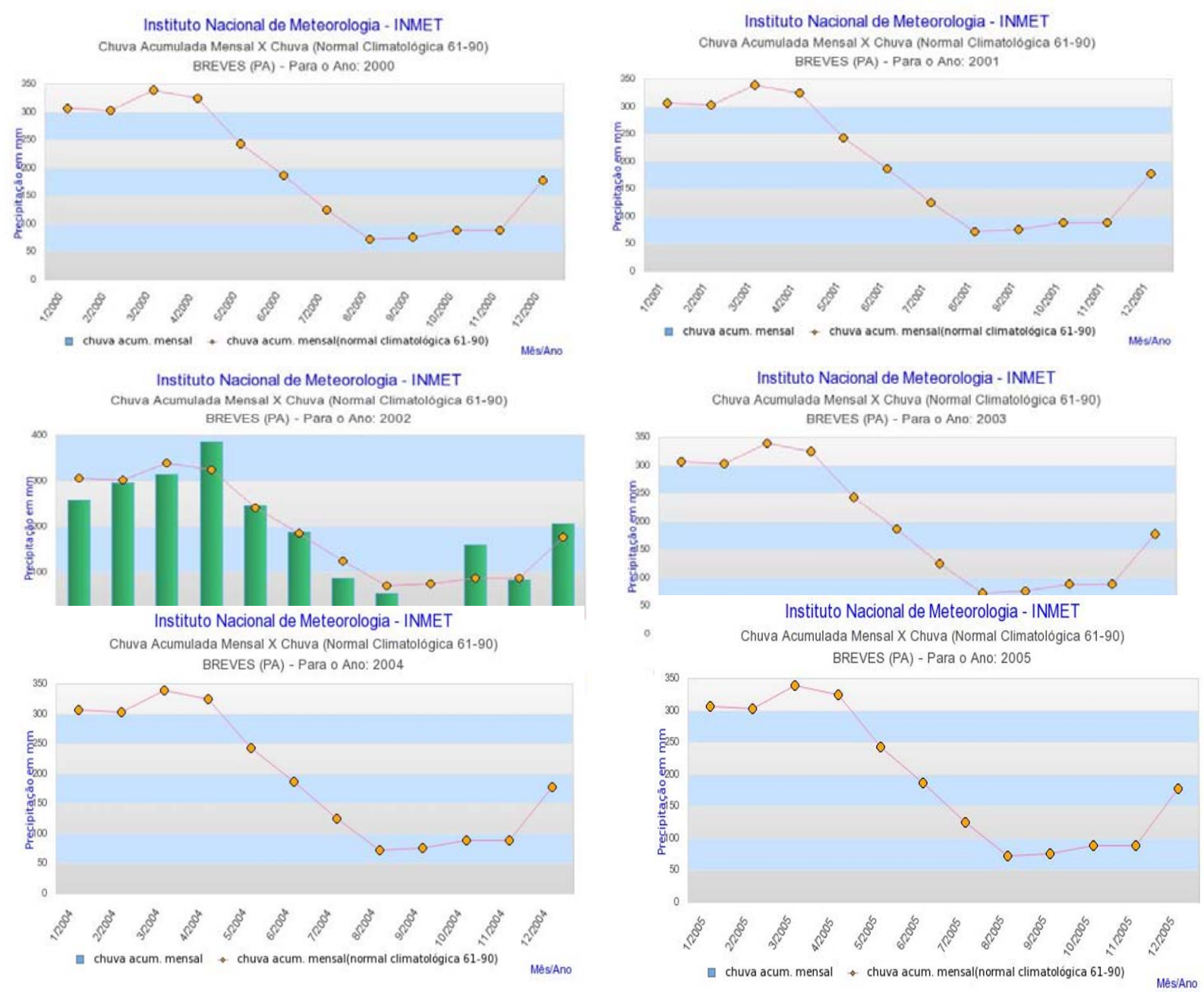

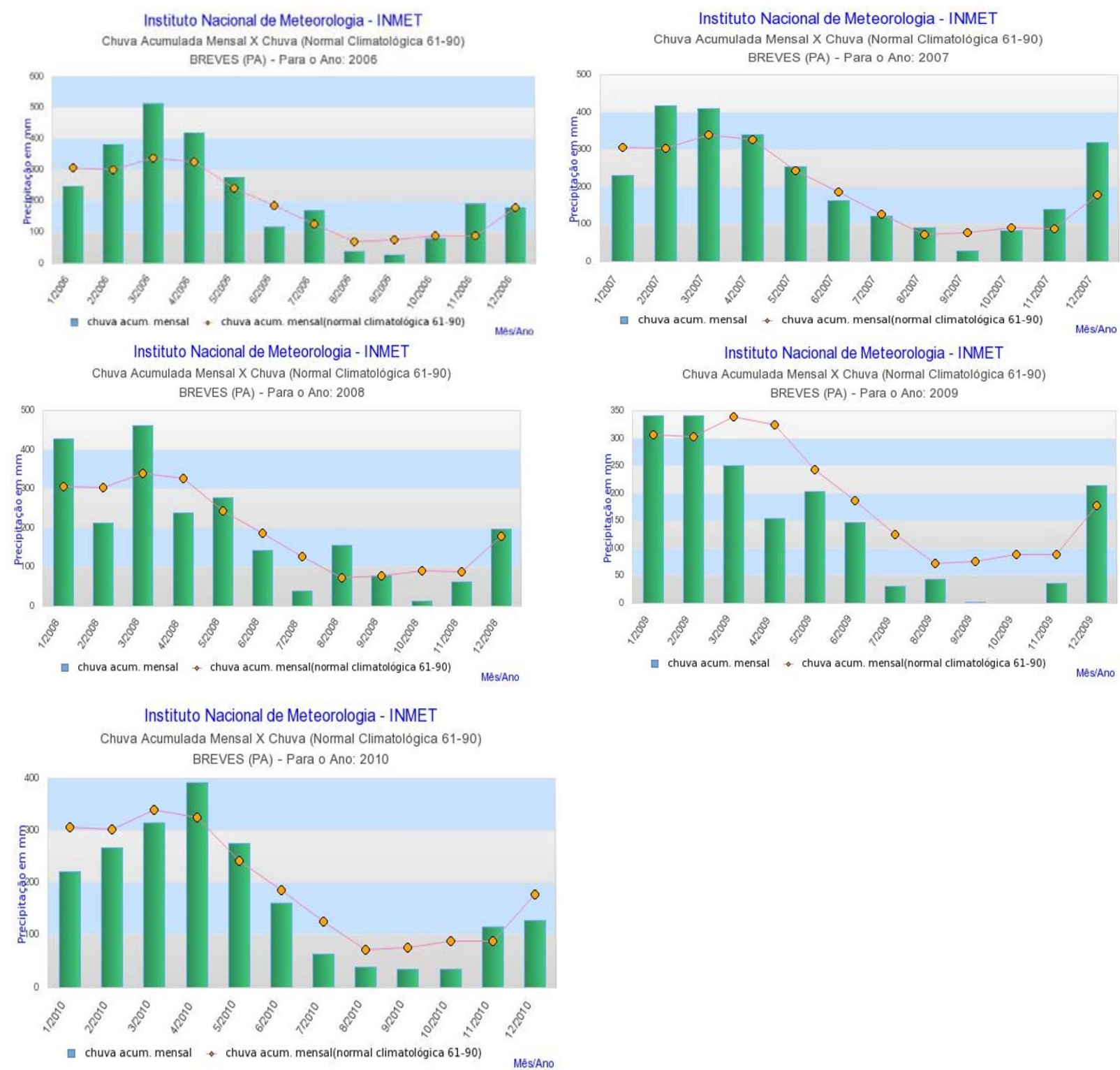

Fonte: INMET, 2017.

\subsection{3 Área total do Telhado}

Não há informações oficiais sobre a área de telhados para a região da Amazônia Ocidental do Brasil. Por conseguinte, a área média de telhados será igual definida por Ghisi et al. (2006): $85 \mathrm{~m}^{2}$ para casas. Com esses dados e a porcentagem de casas existentes na zona rural do município de Breves, é possível obter a área média ponderada do telhado por meio da Equação 3. Nesse caso, não será avaliada a porcentagem de apartamentos, pois foi considerada como área de estudo a zona rural de Breves, onde não existe a tal respectiva unidade.

$\mathrm{RA}=\mathrm{H} \cdot 85+\mathrm{F} \cdot \mathrm{PD} \cdot 3,75$

onde:

RA: área média do telhado por domicílio em cada cidade $\left(\mathrm{m}^{2}\right)$;

$\mathrm{H}$ : porcentagem de casas em cada cidade; 
F: porcentagem de apartamentos em cada cidade;

PD: $n^{\circ}$ da população local $/ n^{\circ}$ de domicílios.

Desse modo, para o cálculo da área total do telhado na zona rural de Breves, consideraram-se apenas as unidades familiares da zona rural fornecidas no ano de 2000, 2007 e 2010, de acordo com o IBGE (2010), conforme tabela 2. Além disso, a partir destes dados calculou-se a porcentagem de casas $(\mathrm{H})$, Área média do Telhado (RA) e Área total do telhado.

Tabela 2: Cálculo da área total do Telhado das unidades domiciliares existentes na zona rural de Breves.

\begin{tabular}{cccccc}
\hline Ano & $\begin{array}{c}\text { População Total } \\
\text { (Urbana+Rural) }\end{array}$ & $\begin{array}{c}\text { Unidade Familiar } \\
\text { Rural (casa) }\end{array}$ & $\begin{array}{c}\text { Porcentagem } \\
\text { de casas }(\mathrm{H})\end{array}$ & $\begin{array}{c}\text { Área média do } \\
\text { telhado-RA }\left(\mathrm{m}^{2}\right)\end{array}$ & $\begin{array}{c}\text { Área total do } \\
\text { Telhado }\left(\mathrm{m}^{2}\right)\end{array}$ \\
\hline 2000 & 80.158 & 39.873 & 49,74 & 58,51 & $4.227,9$ \\
\hline 2007 & 94.458 & 44.498 & 47,11 & 55,42 & $4.004,85$ \\
\hline 2010 & 92.860 & 46.300 & 49,86 & 58,65 & $4.238,1$ \\
\hline
\end{tabular}

\subsubsection{Volume de Chuva}

O volume de chuva foi determinado considerando os dados de precipitação média anual dos anos de 2000, 2007 e 2010, a área total do telhado e o coeficiente de runoff igual a 0,8. Este coeficiente indica que $20 \%$ da água pluvial é perdida pelo descarte para a limpeza do telhado e da evaporação. Assim, o volume de chuva que poderia ser coletado é igual a:

onde:

VR: volume mensal de chuva que poderia ser coletado ( $\left.\mathrm{m}^{3} / \mathrm{mês}\right)$;

R: precipitação média mensal ( $\mathrm{mm} / \mathrm{mês})$;

TRA: área total do telhado $\left(\mathrm{m}^{2}\right)$;

Rc: coeficiente de runoff;

1.000: fator de conversão de litros para $\mathrm{m}^{3}$.

A partir desta equação e dos dados fornecidos da área total do telhado de casas da zona rural de Breves (TRA) e da precipitação média mensal, verificou-se o Volume médio de precipitação mensal a ser coletado pelas residências rurais referentes aos 12 meses do ano de 2000, 2007 e 2010 (Tabela 3).

Tabela 3: Cálculo do Volume médio de precipitação anual a ser coletado (VR).

\begin{tabular}{|c|c|c|}
\hline ANO & Precipitação mensal (mm3/mês) & $\begin{array}{l}\text { VR (volume de precipitação a ser coletado - } \\
\left.\mathbf{m}^{\mathbf{3}} \mathbf{\text { mês}}\right)\end{array}$ \\
\hline jan/00 & 242,5 & 820,21 \\
\hline fev/00 & 404,6 & $1.368,48$ \\
\hline $\mathbf{m a r} / \mathbf{0 0}$ & 467,4 & $1.580,9$ \\
\hline abr/00 & 437,4 & $1.479,43$ \\
\hline mai/00 & 340,4 & $1.151,34$ \\
\hline jun/00 & 221,1 & 747,83 \\
\hline jul/00 & 171,3 & 579,39 \\
\hline ago/00 & 36,7 & 124,13 \\
\hline set/00 & 156,2 & 528,32 \\
\hline out/00 & 101,8 & 344,32 \\
\hline nov/00 & 42,6 & 144,09 \\
\hline dez/00 & 267,8 & 905,78 \\
\hline jan/07 & 230,6 & 738,81 \\
\hline fev/07 & 417,1 & $1.336,34$ \\
\hline mar/07 & 409,7 & $1.312,63$ \\
\hline
\end{tabular}




\begin{tabular}{|c|c|c|}
\hline abr/07 & 339,34 & $1.087,2$ \\
\hline mai/07 & 253,4 & 811,86 \\
\hline jun/07 & 161,8 & 518,39 \\
\hline jul/07 & 120,12 & 384,85 \\
\hline ago/07 & 90,5 & 289,95 \\
\hline set/07 & 26,5 & 84,9 \\
\hline out/07 & 81,5 & 261,12 \\
\hline nov/07 & 138,5 & 443,74 \\
\hline dez/07 & 317,8 & $1.018,19$ \\
\hline jan/10 & 220,6 & 747,94 \\
\hline fev/10 & 267,5 & 906,95 \\
\hline mar/10 & 313,9 & $1.064,27$ \\
\hline abr/10 & 391,7 & $1.328,05$ \\
\hline mai/10 & 276 & 935,77 \\
\hline jun/10 & 161,6 & 547,9 \\
\hline jul/10 & 64,4 & 218,35 \\
\hline ago/10 & 37,8 & 128,16 \\
\hline set/10 & 33,3 & 112,9 \\
\hline out/10 & 34 & 115,28 \\
\hline nov/10 & 114,4 & 387,87 \\
\hline dez/10 & 128,8 & 436,69 \\
\hline
\end{tabular}

\section{Resultados}

Diante destes valores, observou-se que no ano de 2000, o Volume mensal de precipitação a ser coletado se mostra significativo entre os meses de janeiro a junho (Figura 5). No ano de 2007, o período que apresentou uma maior capacidade quanto ao aproveitamento da captação de água de chuva são os meses de janeiro a junho (Figura 6). E no ano de 2010 , este cenário de volume de precipitação a ser produzido se repete nos meses citados anteriormente (Figura 7).

Figura 5: Valores do Volume de precipitação a ser coletado no ano de 2000.

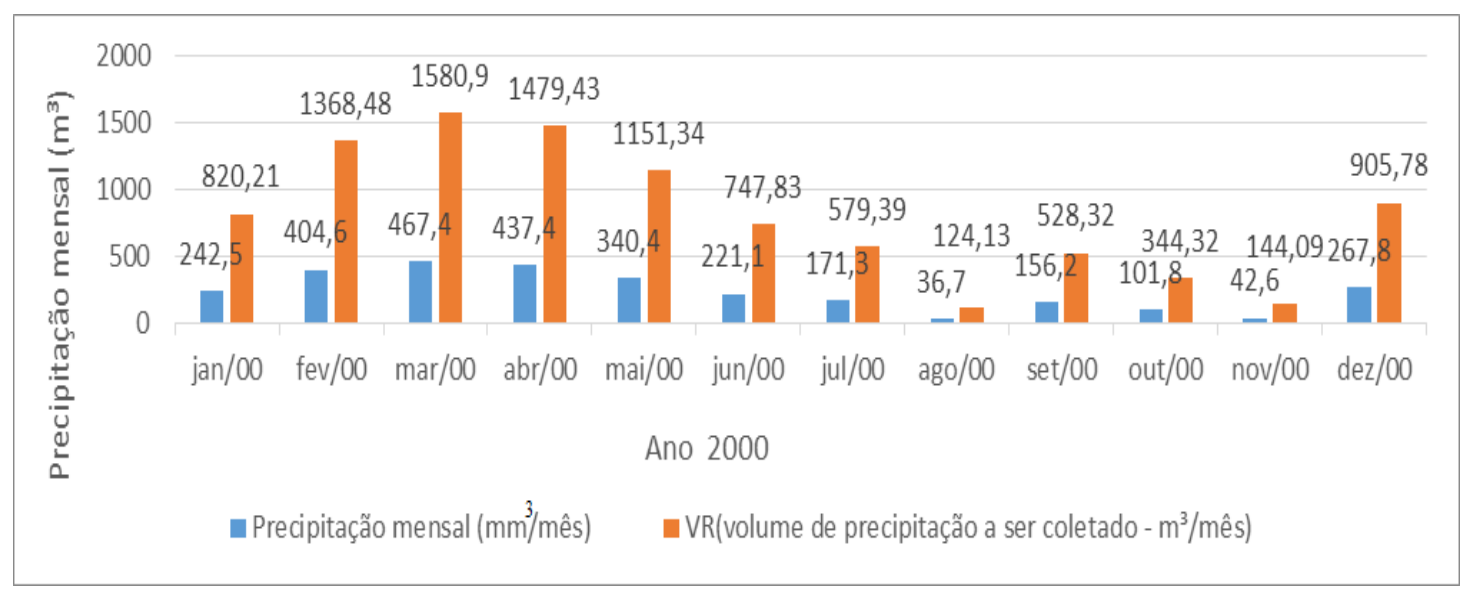


Figura 6: Valores do Volume de precipitação a ser coletado no ano de 2007.

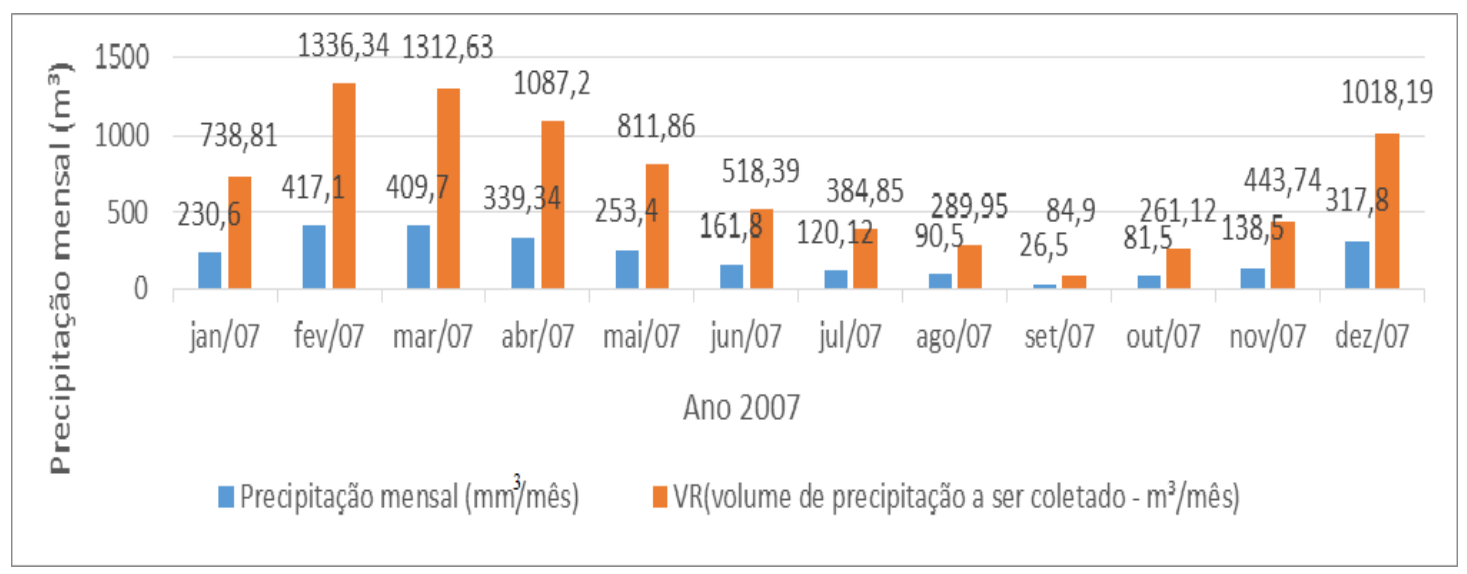

Figura 7: Valores do Volume de precipitação a ser coletado no ano de 2010.

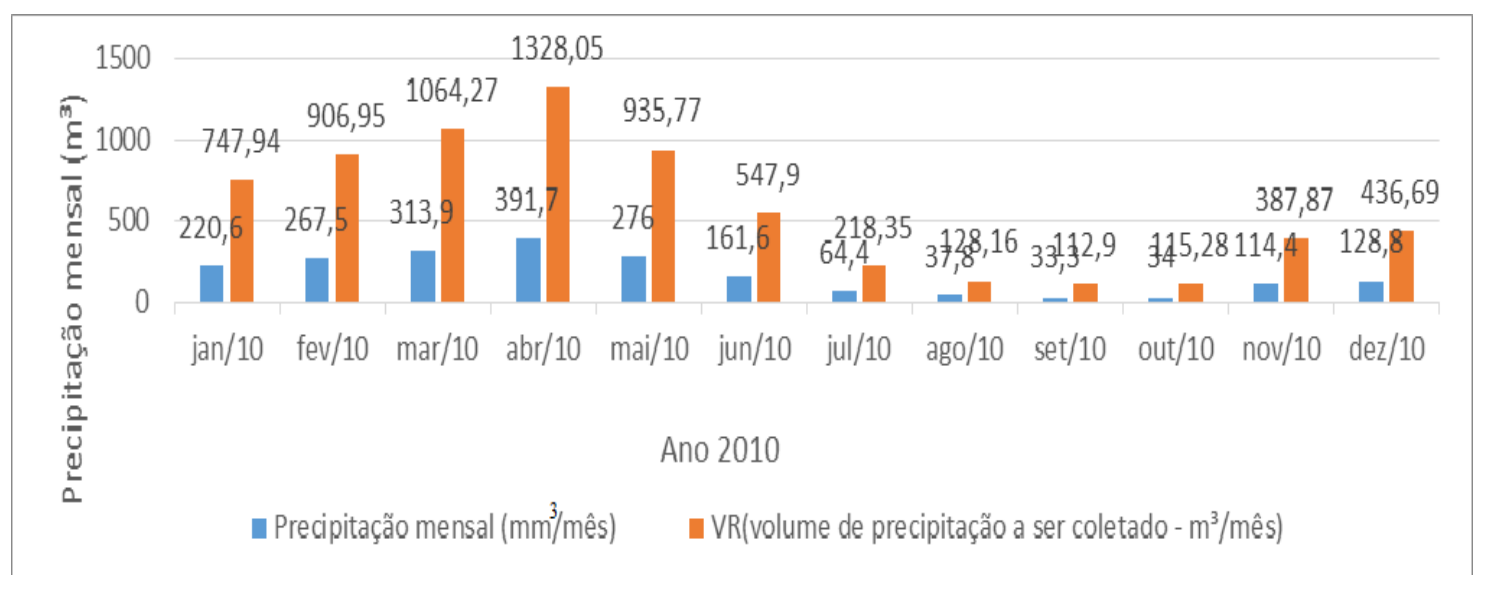

Portanto, mediante estes resultados, foi possível observar que no ano de $2000,84,43 \%$ do volume de precipitação a ser coletado ao longo dos 12 meses, alcançou mais dos $49,74 \%$ das unidades familiares rurais existentes no município de Breves. Já no ano de $2007,82,87 \%$ do VR contempla além do $47,11 \%$ da amostra analisada. E por fim, no ano de $2017,69,40 \%$ do volume de água de chuva a ser coletado atenderia consideravelmente os $49,86 \%$ das unidades rurais. Em termos quantitativos, a adoção desta alternativa diminuiria o déficit de abastecimento das comunidades da zona rural de Breves, que geralmente popularizam grandes extensões em áreas isoladas.

\section{Considerações finais}

A situação do abastecimento de água em Breves é deficiente, ainda que esteja localizado no maior arquipélago fluviomarinho do planeta, a Mesorregião do Marajó, conhecida com a região singular, localizada no estuário dos rios Amazonas e Tocantins, por onde passa 1/4 da água doce dos rios da Terra. Este trabalho demonstra que a água da chuva também pode ser uma alternativa para ampliar o atendimento. Os métodos empregados atualmente para definir o potencial de aproveitamento de água da chuva em várias cidades amazônicas são pertinentes e este trabalho segue a mesma linha de cálculo, considerando os dados de precipitação mensal, a área de captação total e a população rural de Breves.

Para a captação, considerou-se a variabilidade das áreas de telhados da cidade do município entre 55 a $58 \mathrm{~m}^{2}$. A pluviosidade anual de 2000, 2007 e 2010 alcançaram 240,82 mm, 215,57mm, e $170,33 \mathrm{~mm}$, respectivamente, com médias mensais que variam entre 26,5 a $467,4 \mathrm{~mm} / \mathrm{mês}$. Além disso, o volume de precipitação a ser coletado variou entre $84,9 \mathrm{~m}^{3} / \mathrm{mês}$ a $1.580,90 \mathrm{~m}^{3} / \mathrm{mês}$, revelando ser 
considerável como potencial o aproveitamento doméstico a partir da captação da água pluvial para as comunidades rurais, como forma de sanar a carência do acesso ao recurso hídrico para consumo humano, uma vez que a população rural não é atendida (0\%) pelo serviço de abastecimento de água da COSANPA.

\section{Agradecimentos}

Agradecimento ao Programa de Pós-Graduação em Gestão dos Recursos Naturais e Desenvolvimento Local na Amazônia - PPGEDAM, oferecido pela Universidade Federal do Pará, do qual sou mestranda, pelo incentivo à produção cientifica. Ademais, exponho o meu agradecimento a Fundação Amazônia de Amparo a Estudos e Pesquisas, por colaborar financeiramente com as despesas do translado a cidade de Paraíba.

\section{Referências}

AGÊNCIA NACIONAL DE ÁGUA (ANA). (2010). Atlas Brasil: abastecimento urbano de água: panorama nacional. Disponível em: <http://arquivos.ana.gov.br/institucional/sge/CEDOC/ Catalogo/2011/AtlasBrasil-AbastecimentoUrbanodeAgua-PanoramaNacionalv1.pdf>. Acesso em: 05 jul 2018.

BRITO, L. T. de L.; COHIM, E.; GHEYI, H. R.; GNADLINGER, J.; MEDEIROS, S. de S.; PAZ, V. P. da S.; SANTOS, D. B. dos. (2015). Captação, manejo e uso de água de chuva. Disponível em: <file:///C:/Users/Evelyn/Desktop/art.captação\%20de\%20água/captação\%20de\%20água\%20de\%20chu va.pdf>. Acesso em: 10 jul 2018.

CALVIS, M. F.; CARVALHO, J. P. L.; CRUZ, B. E. V. da.; GOMES, D. L.; NASCIMENTO, E. C. do.; REIS, C. dos. (2016). A influência do Programa Bolsa Família nas práticas alimentares das famílias do Território do Marajó, Pará, Brasil. Revista Scientia Plena, v.12, n.6, p. 1-11. Disponível em: <https://www.scientiaplena.org.br/sp/article/view/3110/ 1492>. Acesso em: 04 jul. 2018.

CRISPIM, D. L.; FERNANDES, L. L.; RODRIGUES, R. S. S.; SILVEIRA, R. N. P. de O.; VIEIRA, A. S. de A.. (2016). Espacialização da cobertura do serviço de saneamento básico e do índice de desenvolvimento humano dos municípios do Marajó, Pará. Revista Verde de Agroecologia e Desenvolvimento Sustentável. Pombal - PB, v.11, $\mathrm{n}^{\circ}$ 4, p. 112-122. Disponível em: <http://oaji.net/articles/2016/2238-1481126523.pdf>. Acesso em: 08 jun. 2018.

FUNDAÇÃO AMAZÔNIA DE AMPARO A ESTUDOS E PESQUISAS. (2016). Estatísticas Municipais Paraenses: Breves. Diretoria de Estatística e de Tecnologia e Gestão da Informação, Belém, n. 1, Semestral, jan. / jun., 2016.

GHISI, E.; MONTIBELLER, A.; SCHMIDT, R.W. 2006. Potential for potable water savings by using rainwater: an analysis over 62 cities in Southern Brazil. Building and Environment, 41(2):204-210.

IBGE. Instituto Brasileiro de Geografia e Estatística. (2010). Censo Demográfico 2010. Rio de Janeiro: IBGE. Disponível em: <https://cidades.ibge.gov.br/brasil/pa/breves/panorama>. Acesso em: 10 jul. 2018.

IBGE. Instituto Brasileiro de Geografia e Estatística. 2017. Censo Demográfico. Rio de Janeiro: IBGE. Disponível em: <https://cidades.ibge.gov.br/brasil/pa/breves/panorama>. Acesso em: 15 jul. 2018.

INMET. Instituto Nacional de Meteorologia. (2011). Banco de dados Meteorológicos para o ensino e pesquisa.

Disponível

em: <http://www.inmet.gov.br/projetos/rede/pesquisa/gera_serie_txt_mensal.php?\&mRelEstacao=82188\&bt

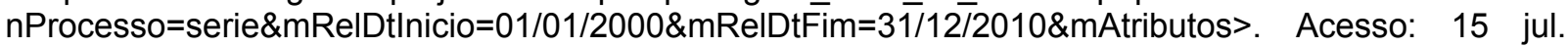
2018.

LIMA, A. A. M.; OLIVEIRA, L. L.; FONTINHAS, R. L.; LIMA, R. J. S. (2004). Ilha do Marajó: revisão histórica, hidroclimatologia, bacias hidrográficas e propostas de gestão. Relatório Técnico. Secretaria Executiva de Ciência Tecnologia e Meio Ambiente - Núcleo de Hidrometereologia (SECTAM/NHM), Belém. Disponível em: <https://www.cea-unesp.org.br/holos/article/viewFile/331/290>. Acesso em: 02 jul. 2018. 
PRODANOV, C. C.; FREITAS, E. C. de. (2013). Metodologia do trabalho científico: métodos e técnicas da pesquisa e do trabalho acadêmico. 2. ed. Novo Hamburgo: Feevale. Disponível em: <http://www.feevale.br/Comum/midias/8807f05a-14d0-4d5b-b1ad-1538f3aef538/Ebook\%20Metodologia\%20do\%20Trabalho\%20Cientifico.pdf>. Acesso em: 10 jun. 2018.

SNIS. Institucional. Brasília, DF, 2015 Disponível em: <http://www.snis.gov.br/institucional-snis> Acesso em: 1 jun. 2016a. 